\title{
Desempenho animal, produção de forragem e características estruturais dos capins marandu e xaraés submetidos a intensidades de pastejo ${ }^{1}$
}

\section{Renata Santos Flores ${ }^{2}$, Valéria Pacheco Batista Euclides ${ }^{3}$, Maria Paula Cavuto Abrão ${ }^{4}$, Sandra Galbeiro ${ }^{5}$, Gelson dos Santos Difante ${ }^{6}$, Rodrigo Amorim Barbosa ${ }^{7}$}

1 Projeto financiado pela Embrapa Gado de Corte e Fundect.

${ }^{2}$ Mestre em Ciência Animal pela UFMS, Bolsista DTI do CNPq-Embrapa Gado de Corte, BR 262, Km 4, Caixa Postal 154, CEP: 79002-970, Campo Grande, MS

${ }^{3}$ Embrapa Gado de Corte. Bolsista do CNPq

4 Mestranda em Ciência Animal pela UFMS

${ }^{5}$ Doutoranda em Zootecnia pela UEM. Bolsista da Fundect.

${ }^{6}$ Bolsista CAPES de Pós-doutorado - Embrapa Gado de Corte.

${ }^{7}$ Embrapa Gado de Corte.

RESUMO - Os objetivos foram avaliar a produção de forragem, as características estruturais, a ingestão de forragem, o comportamento de ingestão e o desempenho animal de bovinos em pastos de capins marandu e xaraés submetidos a três intensidades de pastejo. O período experimental foi de outubro de 2005 a junho de 2006 em área de 8 hectares, divididos em 12 piquetes de 0,67 hectares. Foram avaliados dois cultivares de B. brizantha (Marandu e Xaraés) e três intensidades de pastejo (15, 30 e $45 \mathrm{~cm}$ de altura do dossel). O delineamento experimental foi de blocos completos casualizados com parcelas subdivididas com duas repetições. As parcelas principais foram constituídas pelos cultivares e as subparcelas pelas intensidades de pastejo. O método de pastejo utilizado foi de lotação contínua com taxa de lotação variável. Cada piquete foi pastejado por três novilhos e por animais reguladores, utilizados para ajustar as alturas do dossel. As alturas foram monitoradas duas vezes por semana. Os pastos foram amostrados a cada 28 dias para estimativa da massa de forragem, da taxa de acúmulo de forragem, das características estruturais e do valor nutritivo. Os animais foram pesados a cada 28 dias. O consumo de matéria seca foi estimado no verão e outono, e o comportamento de ingestão no verão. A taxa de acúmulo e o ganho médio diário decresceu à medida que aumentou a intensidade de pastejo nos pastos de capins xaraés e marandu. $\mathrm{O}$ consumo de forragem pelos animais nos pastos de capim xaraés foi limitado pela variação na estrutura do dossel. Considerando as características estruturais do dossel, o consumo de forragem e a produtividade, estes capins requerem práticas de manejo diferenciadas: o capim-marandu deve ser manejado entre 25 e $40 \mathrm{~cm}$ de altura e o capim-xaraés a $40 \mathrm{~cm}$.

Palavras-chave: acúmulo de forragem, Brachiaria brizantha, consumo de forragem, manejo de pastagem, oferta de forragem, valor nutritivo

\section{Animal performance, forage yield and structural characteristics in the palisadegrass cvs. marandu and xaraés submitted to grazing intensities}

\begin{abstract}
The objectives were to evaluate the forage yield, the structural characteristics, the herbage intake, the grazing behavior and beef cattle performance in the palisadegrass cvs. Marandu and Xaraés pastures submitted to three grazing intensities. The experiment was carried out at Embrapa Gado de Corte. The experimental period was from October 2005 to June 2006. The area was of 8 ha, divided in 12 paddocks of 0.67 ha. Two cultivars of palisadegrass, Marandu and Xaraés, and three grazing intensities, 15, 30, and $45 \mathrm{~cm}$ of sward height were evaluated. The experimental design was randomized block in a split plot arrangement and two replications. The main plot was constituted by cultivars and the subplot by the grazing intensities. The grazing was continuously stocking with variable stocking rate. Each paddock was grazed by three steers and regulating animals were utilized to adjust the sward heights. The sward heights were monitored twice per week. The grass was sampled each 28 days to estimate the herbage yield, herbage accumulation rate, pasture structural characteristics, and nutritive value. Animals were weighed each 28 days. The dry matter intake was estimated in the summer and the autumn, and the grazing behavior in the summer. Herbage accumulation and average daily gain decreased as the grazing intensities increased for both palisadegrass cvs. Xaraés and Marandu. The forage intake for the animals in xaraés grass pasture was limited by the variation in the sward structure. Based on the sward structural characteristics, forage intake and the productivity, these grasses require differentiated management. Marandu grass must be managed between 25 and $40 \mathrm{~cm}$ of height and xaraés grass at $40 \mathrm{~cm}$.
\end{abstract}

Key Words: Brachiaria brizantha, forage accumulation, forage allowance, forage intake, nutritive value, pasture management 


\section{Introdução}

Nos últimos anos, o capim-marandu destacou-se nos sistemas de produção de bovinos, o que resultou em aumento considerável de área plantada (Macedo, 2005). No entanto, em virtude do grande potencial de produção desta gramínea, a produtividade, a eficiência e a sustentabilidade de sua utilização nos sistemas de produção estão aquém do seu potencial ótimo, principalmente em virtude da redução na fertilidade do solo e do inadequado manejo do pastejo desta planta forrageira.

O cultivar Xaraés, lançado em 2003 é mais uma opção para a diversificação das gramíneas forrageiras e, apesar de promover desempenho animal inferior ao obtido com o cultivar Marandu, possui vantagens, como maior velocidade de rebrota e maior produção de forragem, o que garante mais alta capacidade de suporte e maior produtividade por área (Euclides et al., 2005).

Segundo Hodgson (1990), a essência do manejo do pastejo consiste em encontrar balanço eficiente entre o crescimento da planta, o seu consumo e a produção animal para manter estável o sistema de produção. Nesse contexto, Gomide \& Gomide (2001) sugeriram que a planta forrageira seja utilizada de forma mais racional, por meio de práticas de manejo sustentáveis que permitam alta produtividade e aproveitamento eficiente da forragem produzida, de modo a gerar máxima produtividade animal. Assim, conciliar alta produção de forragem e perenidade do pasto com elevada produção animal exige adequação do manejo da desfolhação e o estabelecimento de um equilíbrio que respeite os limites específicos de cada espécie forrageira, ressaltando-se que somente após a associação estável entre planta e ambiente na pastagem, a consideração do componente animal como gerador de produção se torna importante. Esse autor ressaltou que, para cada espécie e/ou cultivar de planta forrageira, existe uma amplitude de condições de pasto específica para que as metas de produção animal sejam alcançadas.

Pesquisas recentes com diversas gramíneas tropicais (Carnevalli et al., 2000, 2001a,b, 2006; Andrade, 2003; Sarmento, 2003; Sbrissia, 2004; Difante, 2005; Barbosa et al., 2007) confirmaram que a estratégia de manejo baseada no monitoramento e no controle da altura do dossel gera relações bastante consistentes entre as respostas da planta forrageira e dos animais e permite o entendimento dos efeitos das variações estruturais do dossel sobre a produção e a persistência da planta e o desempenho animal.

Assim, os objetivos neste estudo foram avaliar a produção de forragem, as características estruturais do dossel, a ingestão de forragem, o comportamento de ingestão e o desempenho animal de bovinos em pastos de capim-marandu e capim-xaraés submetidos a três intensidades de pastejo.

\section{Material e Métodos}

O experimento foi realizado na Embrapa Gado de Corte, Campo Grande, Mato Grosso do Sul (latitude 20²7' S, longitude $54^{\circ} 37^{\prime} \mathrm{W}$ e altitude $530 \mathrm{~m}$ ), no período de outubro de 2005 a junho de 2006. A coleta de dados iniciou-se em janeiro de 2006, totalizando 160 dias, divididos em dois períodos, um correspondendo ao verão (janeiro, fevereiro e março) e o outro ao outono (abril, maio e junho).

O clima, segundo classificação de Köppen, é do tipo tropical chuvoso de savana, subtipo Aw, caracterizado pela distribuição sazonal das chuvas, com ocorrência bem definida do período seco durante os meses mais frios do ano e um período chuvoso durante os meses de verão. Os dados de temperatura e precipitação utilizados no cálculo do balanço hídrico (Figura 1) durante o período experimental foram registrados pela estação meteorológica da Embrapa Gado de Corte, a aproximadamente 800 m da área experimental.

O solo da área experimental é classificado como Latossolo Vermelho Distrófico (Embrapa, 1999) e caracteriza-se por textura argilosa, pH ácido, baixa saturação por bases, altos teores de alumínio e baixo teor de fósforo. Os pastos foram estabelecidos em novembro de 2000 e, nos meses de março de 2001 a setembro de 2005, foram pastejados. Em novembro de 2005, realizaram-se uma adubação de manutenção com $200 \mathrm{~kg} / \mathrm{ha}$ da fórmula 0-20-20 e uma adubação nitrogenada com $90 \mathrm{~kg} /$ ha de nitrogênio na forma de uréia, parcelada em duas vezes, a primeira em 20/12/2005 e a segunda no dia 28/2/2006.

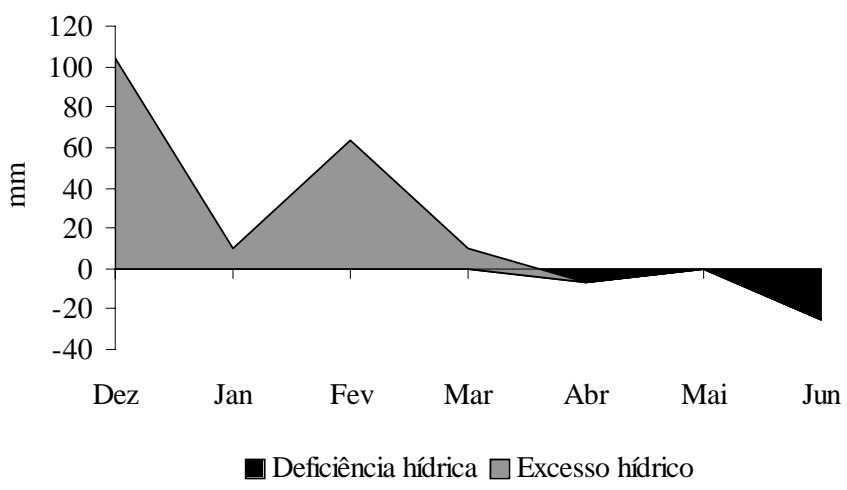

Figura 1 - Balanço hídrico mensal durante o período de dezembro de 2005 a junho de 2006 . 
A área utilizada no experimento foi de 8 ha, subdivididos em dois blocos. Cada bloco foi dividido em seis piquetes de 0,67 hectares. Próximo à área experimental, foram utilizadas áreas-reserva de capim-massai para manutenção dos animais reguladores quando não eram necessários na área experimental para ajuste das alturas pretendidas. Avaliaram-se dois cultivares de $B$. brizantha (Marandu e Xaraés) e três intensidades de pastejo (15, 30 e $45 \mathrm{~cm}$ de altura do dossel). O delineamento experimental foi o de blocos completos casualizados com parcelas subdivididas com duas repetições. As parcelas principais foram constituídas pelos cultivares de Brachiaria brizantha e as subparcelas, pelas intensidades de pastejo.

Em outubro de 2005, a altura média dos pastos era de aproximadamente $50 \mathrm{~cm}$. Assim, optou-se por roçar os pastos com alturas do dossel de 15 e $30 \mathrm{~cm}$, os quais foram rebaixados para 20 e $35 \mathrm{~cm}$, respectivamente. Em novembro de 2005, todos os pastos foram submetidos ao pastejo para gerar as alturas pretendidas.

O método de pastejo utilizado foi o de lotação contínua com taxa de lotação variável. Cada piquete foi pastejado por três novilhos mestiços (animais avaliadores) com peso inicial médio de $250 \mathrm{~kg}$, distribuídos ao acaso. Todos os animais receberam água e mistura mineral completa à vontade, além de manejo sanitário, conforme recomendado pela Embrapa Gado de Corte.

A altura do dossel foi medida utilizando-se uma régua de $1 \mathrm{~m}$, graduada em centímetros. Duas vezes por semana, foram medidos 60 pontos aleatórios por piquete distribuídos ao longo de quatro transectas, cada uma com 15 pontos. A altura do dossel em cada ponto correspondeu à altura média da curvatura das folhas superiores em torno da régua.

A massa de forragem foi estimada a cada 28 dias cortando-se 15 amostras de $1 \mathrm{~m}^{2}$, rente ao solo, alocadas ao acaso. As amostras foram divididas em duas partes: uma foi seca em estufa a $65^{\circ} \mathrm{C}$ e pesada para estimativa da massa seca total (MST) e a outra foi utilizada para formação de amostras compostas (a cada cinco amostras, formou-se uma amostra composta). As amostras compostas foram separadas manualmente em lâmina foliar, colmo (colmo e bainha) e material morto. Posteriormente, foram secas em estufa a $65^{\circ} \mathrm{C}$ e pesadas para obtenção das relações lâminas foliares:colmo, lâminas foliares:material morto e material verde:material morto. A densidade volumétrica foi calculada dividindo-se a massa de matéria seca pela altura do dossel.

O acúmulo de forragem foi estimado utilizando-se três gaiolas $\left(1 \mathrm{~m}^{2}\right)$ de exclusão por piquete. A cada 28 dias, as gaiolas foram posicionadas em pontos representativos da altura média do dossel, com massa e composição morfológica semelhantes às áreas sob pastejo. As massas de matéria seca, dentro e fora da gaiola, foram obtidas por corte rente ao solo. Depois de cada corte, as gaiolas foram realocadas em outros pontos do piquete seguindo a mesma metodologia. O acúmulo de forragem ( $\mathrm{kg} / \mathrm{ha}$ de matéria seca) foi obtido pela diferença entre as massas de forragem observadas dentro e fora da gaiola. Para a estimativa da taxa de acúmulo de forragem ( $\mathrm{kg} /$ ha.dia), dividiu-se o acúmulo de forragem por 28.

A cada 28 dias, a oferta de matéria seca (kg de matéria seca por $100 \mathrm{~kg}$ de peso corporal) foi calculada utilizando-se a soma da massa de matéria seca presente no piquete e o acúmulo de forragem no período dividida pelo total do peso corporal mantido no piquete no mesmo período. A oferta de lâmina foliar (kg de matéria seca de lâmina foliar por 100 kg de peso corporal) foi calculada da mesma forma, considerando apenas esse componente da planta.

O valor nutritivo foi estimado apenas na fração lâminas foliares para estimativa dos teores de proteína bruta (PB), fibra em detergente neutro (FDN) e lignina em detergente ácido (LDA) e da digestibilidade in vitro da matéria orgânica (DIVMO) utilizando-se o Sistema de Espectrofotometria de Reflectância no Infravermelho Proximal (NIRS), de acordo com procedimentos de Marten et al. (1985).

Todos os animais (avaliadores e reguladores) foram pesados a cada 28 dias, com jejum prévio de 16 horas. A qualidade do pasto foi determinada por meio do ganho diário de peso dos animais avaliadores. Também foi computado o número de dias que os animais reguladores permaneceram na pastagem. Os números de animais avaliadores e reguladores, combinados, possibilitaram as estimativas da taxa de lotação e da produção por área.

O consumo de matéria seca foi estimado em duas ocasiões (no final do verão e no final do outono), segundo metodologia descrita por Valadares Filho et al. (2005), por meio da produção fecal de matéria seca (PF), obtida com o fornecimento de óxido crômico $\left(\mathrm{Cr}_{2} \mathrm{O}_{3}\right)$ como indicador externo. Durante oito dias, foram fornecidos diariamente $10 \mathrm{~g}$ de $\mathrm{Cr}_{2} \mathrm{O}_{3}$, em dose única; nos três últimos dias, foram realizadas as coletas de fezes. No primeiro dia, as fezes foram coletadas pela manhã, no segundo dia, por volta do meio-dia e, no terceiro e último dia, no período da tarde. As fezes foram coletadas diretamente no reto e congeladas a $-10^{\circ} \mathrm{C}$.

Posteriormente, as amostras de fezes foram descongeladas a temperatura ambiente e acondicionadas em bandejas de alumínio para secagem em estufa a $50^{\circ} \mathrm{C}$. Depois de 
secas, as amostras foram moídas ( $1 \mathrm{~mm}$ ), compostas por animal e analisadas para estimativa do teor de cromo em espectrofotômetro de absorção atômica, conforme metodologia descrita por Willians et al. (1962).

Como os pastos foram acidentalmente queimados quando se iniciavam as avaliações do comportamento ingestivo correspondente ao outono, o tempo de pastejo e a taxa de bocado apresentados neste trabalho referem-se somente ao período de verão. O tempo de pastejo (minutos por dia) foi estimado, durante 72 horas, nos três animais avaliadores, equipados de vibracorderes adaptados em buçais (Stobbs, 1970). Seqüencialmente, as cartelas registradoras foram retiradas e, com o auxílio de um cronógrafo, computou-se o tempo de pastejo por períodos de 24 horas.

Nesse mesmo período, as taxas de bocado foram avaliadas nos mesmos animais nos períodos de maior atividade de pastejo, quando foi determinado o tempo gasto pelo animal para realizar 20 bocados (Hodgson, 1982). Essas observações foram realizadas por dois observadores, de modo que cada um repetiu a avaliação dez vezes em cada animal. A taxa de bocado (bocados/minuto) foi calculada como o quociente entre 20 bocados e o tempo gasto para sua realização.

Os dados foram agrupados por estação do ano (verão e outono) e analisados em um modelo matemático contendo os efeitos de bloco, cultivar, altura do dossel, estação do ano e suas interações. Para as análises do tempo de pastejo, da taxa de bocado e da produtividade, utilizou-se um modelo matemático contendo os efeitos de bloco, de cultivar, altura do dossel e a interação entre eles. Todas as análises foram feitas pelo método dos quadrados mínimos utilizando-se o procedimento "General Linear Model” (SAS, 1996). Os comandos RANDOM e TEST foram utilizados para identificação e realização dos testes apropriados para cada variável independente. A comparação de médias foi realizada pelo teste de Tukey a 5\% de significância. No caso de interações significantes, a comparação de médias foi realizada por meio de contrastes adotando-se 5\% de nível de significância.

\section{Resultados e Discussão}

Ao longo do período experimental, as médias de alturas de dossel mantiveram-se em torno de $14 \%$ abaixo do pretendido $(25,9 \pm 2,4 \mathrm{~cm}$ e 39,2 $\pm 2,9 \mathrm{~cm})$, exceto as do capimmarandu na altura de $15 \mathrm{~cm}$ do dossel (Tabela 1 ), o que pode ser explicado pelas elevadas taxas de lotação no início do período experimental na tentativa de gerar as alturas pretendidas (Tabela 2). Em virtude da redução da taxa de acúmulo de forragem ao longo do período experimental e da pequena dimensão dos piquetes ( 0,67 ha), foi difícil a manutenção dos três animais avaliadores ao longo do experimento, uma vez que se tornou necessária a retirada progressiva dos animais avaliadores da área experimental. Ao final do período experimental, constava apenas um animal-avaliador por unidade experimental (Tabela 2).

Mesmo reduzindo a taxa de lotação (Tabela 2), não foi possível manter as condições de pasto planejadas, de 15, 30 e $45 \mathrm{~cm}$ de altura do dossel. Assim, as intensidades de pastejo impostas ao longo do período experimental corresponderam às alturas reais de aproximadamente 15 , 25 e $40 \mathrm{~cm}$ de altura do dossel.

Os pastos dos capins marandu e xaraés apresentaram valores semelhantes $(\mathrm{P}>0,10)$ de massas de matéria seca total (MST), matéria seca verde (MSV) e matéria seca de lâminas foliares (MSLF) e de taxas de acúmulo de matéria seca (TAMS). Também não houve interações $(\mathrm{P}>0,05)$ entre os efeitos de cultivar e estação do ano; de altura do dossel e estação do ano; e de cultivar, altura do dossel e estação do ano para as massas MST, MSV e MSLF. Apesar da maior $(\mathrm{P}<0,01)$ taxa de acúmulo de forragem durante o verão, não foram observadas diferenças significativas $(\mathrm{P}>0,08)$ para as massas de MST, MSV e MSLF, conseqüência do manejo adotado para manter as alturas dos pastos. As médias e o desvio-padrão das taxas de acúmulo de matéria seca foram de 103,9 e 75,0 (7,23) kg/ha.dia, respectivamente para verão e outono. O maior acúmulo de forragem durante o verão pode estar relacionado às melhores condições climáticas

Tabela 1 - Alturas dos dosséis de pastos de capins marandu e xaraés durante o período experimental

\begin{tabular}{|c|c|c|c|c|c|c|}
\hline \multirow[b]{2}{*}{ Meses } & \multicolumn{3}{|c|}{ Capim-marandu } & \multicolumn{3}{|c|}{ Capim-xaraés } \\
\hline & $15 \mathrm{~cm}$ & $30 \mathrm{~cm}$ & $45 \mathrm{~cm}$ & $15 \mathrm{~cm}$ & $30 \mathrm{~cm}$ & $45 \mathrm{~cm}$ \\
\hline Janeiro & $17,7 \pm 1,17$ & $26,1 \pm 2,55$ & $40,3 \pm 2,89$ & $17,1 \pm 1,56$ & $30,4 \pm 1,59$ & $41,5 \pm 2,75$ \\
\hline Fevereiro & $18,4 \pm 2,24$ & $26,5 \pm 2,58$ & $40,0 \pm 3,76$ & $14,5 \pm 1,22$ & $27,1 \pm 2,37$ & $41,6 \pm 2,90$ \\
\hline Março & $16,4 \pm 1,89$ & $26,6 \pm 2,23$ & $38,0 \pm 3,77$ & $12,5 \pm 1,68$ & $25,0 \pm 2,17$ & $41,1 \pm 1,77$ \\
\hline Verão & $17,3 \pm 2,61$ & $26,5 \pm 3,61$ & $39,1 \pm 4,24$ & $15,3 \pm 1,83$ & $28,0 \pm 2,60$ & $41,7 \pm 2,54$ \\
\hline Abril & $17,1 \pm 2,54$ & $26,2 \pm 2,50$ & $36,4 \pm 3,32$ & $13,0 \pm 1,47$ & $23,4 \pm 1,21$ & $41,8 \pm 2,31$ \\
\hline Maio & $15,9 \pm 2,51$ & $25,2 \pm 1,82$ & $36,3 \pm 3,40$ & $13,6 \pm 1,98$ & $26,1 \pm 1,58$ & $41,1 \pm 1,30$ \\
\hline Junho & $15,0 \pm 1,73$ & $24,2 \pm 1,19$ & $37,0 \pm 2,74$ & $12,4 \pm 1,14$ & $26,1 \pm 1,85$ & $41,2 \pm 0,91$ \\
\hline Outono & $16,3 \pm 2,43$ & $25,5 \pm 2,19$ & $36,4 \pm 3,45$ & $12,8 \pm 1,22$ & $25,1 \pm 1,37$ & $40,6 \pm 0,48$ \\
\hline Média & $16,9 \pm 2,57$ & $26,1 \pm 3,10$ & $37,9 \pm 4,11$ & $13,7 \pm 2,11$ & $26,1 \pm 2,72$ & $41,4 \pm 2,09$ \\
\hline
\end{tabular}


Tabela 2 - Taxa de lotação em pastos de capins marandu e xaraés, durante o período experimental (piquetes de 0,67 ha)

\begin{tabular}{lcccccccc}
\hline & \multicolumn{3}{c}{ Capim-marandu } & & \multicolumn{3}{c}{ Capim-xaraés } \\
\cline { 2 - 5 } \cline { 7 - 8 } Meses & $15 \mathrm{~cm}$ & $30 \mathrm{~cm}$ & $45 \mathrm{~cm}$ & & $15 \mathrm{~cm}$ & $30 \mathrm{~cm}$ & $45 \mathrm{~cm}$ \\
\hline Janeiro & 6,4 & 6,3 & 4,1 & & 8,4 & 7,1 & 4,7 \\
Fevereiro & 4,7 & 3,2 & 3,0 & & 5,3 & 3,5 & 3,0 \\
Março & 4,5 & 3,0 & 3,0 & & 4,2 & 3,0 & 3,0 \\
Abril & 3,1 & 3,0 & 3,0 & & 3,3 & 3,0 & 3,0 \\
Maio & 2,8 & 2,7 & 2,5 & & 2,5 & 2,1 & 2,0 \\
Junho & 1,5 & 1,2 & 1,0 & & 1,5 & 1,5 & 1,0 \\
\hline
\end{tabular}

(Figura 1) neste período. Esse padrão de variação também foi observado por Molan (2004), Carnevalli et al. (2006) e Barbosa et al. (2007) para diversas gramíneas tropicais.

Observou-se também efeito da altura do dossel $(\mathrm{P}<0,05)$ sobre a TAMS e as massas de MST, MSV e MSLF e, ainda, da interação $(\mathrm{P}<0,01)$ cultivar $\times$ altura do dossel sobre a massa de MSLF (Tabela 3). Independentemente do cultivar, os pastos manejados a $40 \mathrm{~cm}$ de altura apresentaram as maiores massas de MST e de MSV, que decresceram de acordo com a altura do dossel. Relação positiva entre altura do dossel e massa de forragem para espécies de gramíneas também foi observada por outros autores (Fagundes et al., 1999; Lupinacci, 2002; Barbosa et al., 2006; Zeferino, 2006).

A maior taxa de acúmulo de forragem foi observada para o pasto manejado a $40 \mathrm{~cm}$, a menor para o manejado a $15 \mathrm{~cm}$ e a intermediária para aquele manejado a $30 \mathrm{~cm}$ de altura do dossel (Tabela 3). No entanto, Molan (2004) observou que pastos de capim-marandu adubados com $150 \mathrm{~kg} / \mathrm{ha}$ de $\mathrm{N} \mathrm{e}$ manejados de 10 a $30 \mathrm{~cm}$ apresentaram taxas de acúmulo de forragem equivalentes, porém superiores às do pasto manejado a $40 \mathrm{~cm}$. Esse autor atribuiu este resultado a erros de medição do acúmulo de forragem, decorrentes da utilização de gaiolas de exclusão. Neste estudo, a menor TAMS observada no pasto com maior intensidade de pastejo provavelmente foi conseqüência da maior remoção de folhas (Tabela 3) e da maior dependência de nitrogênio para sua rebrotação, uma vez que, independentemente da intensidade de pastejo, a quantidade de nitrogênio aplicada foi a mesma (90 kg/ha).

A massa de MSLF do pasto de capim-marandu diminuiu conforme a altura do dossel. No pasto de capim-xaraés, houve decréscimo na massa de MSLF da altura de 40 para $25 \mathrm{~cm}$ do dossel, no entanto, nas alturas de 25 e $15 \mathrm{~cm}$ do dossel, as MSLF foram semelhantes (Tabela 3). A maior MSLF em pasto com menor intensidade de pastejo era esperada, uma vez que em maior altura de dossel os animais não precisam explorar os estratos inferiores e, conseqüentemente, deixam acumular maior quantidade de tecido foliar.
Tabela 3 - Massas de matéria seca total, matéria seca verde e matéria seca de lâminas foliares e taxa de acúmulo de forragem em pastos de capins marandu e xaraés manejados em diversas alturas de dossel

\begin{tabular}{|c|c|c|c|c|}
\hline & \multicolumn{3}{|c|}{ Altura $(\mathrm{cm})$} & \multirow[b]{2}{*}{ Erro-padrão } \\
\hline & 15 & 25 & 40 & \\
\hline \multicolumn{5}{|c|}{ Matéria seca total $(\mathrm{kg} / \mathrm{ha})$} \\
\hline Marandu & 3.200 & 4.450 & 5.770 & 322 \\
\hline Xaraés & 2.540 & 2.660 & 5.000 & 322 \\
\hline Média & $2.870 \mathrm{c}$ & $3.550 \mathrm{~b}$ & $5.380 \mathrm{a}$ & 228 \\
\hline \multicolumn{5}{|c|}{ Matéria seca verde (kg/ha) } \\
\hline Marandu & 1.785 & 2.475 & 3.300 & 170 \\
\hline Xaraés & 1.210 & 1.515 & 3.075 & 170 \\
\hline Média & $1.495 \mathrm{c}$ & $1.995 b$ & $3.187 a$ & 120 \\
\hline & \multicolumn{4}{|c|}{ Matéria seca de lâminas foliares (kg/ha) } \\
\hline Marandu & $880 \mathrm{Ac}$ & $1.220 \mathrm{Ab}$ & $1.470 \mathrm{Aa}$ & 88 \\
\hline Xaraés & $590 \mathrm{Bb}$ & 740Bb & $1.505 \mathrm{Aa}$ & 88 \\
\hline \multirow[t]{2}{*}{ Média } & 735 & 980 & 1.485 & 63 \\
\hline & \multicolumn{4}{|c|}{ Taxa de acúmulo de forragem (MS/ha.dia) } \\
\hline Marandu & 69,3 & 83,5 & 97,6 & 12,5 \\
\hline Xaraés & 75,1 & 90,7 & 120,4 & 12,5 \\
\hline Média & $72,2 b$ & $87,1 \mathrm{ab}$ & 109,0 a & 8,9 \\
\hline
\end{tabular}

Médias seguidas de mesma letra minúscula na linha, e maiúscula na coluna não diferem $(P<0,05)$ pelo teste Tukey.

Além disso, exceto quando mantidos a $40 \mathrm{~cm}$, os pastos de capim-marandu apresentaram maiores MSLF em comparação aos de capim-xaraés (Tabela 3), o que provavelmente está relacionado ao porte mais elevado deste capim (Silveira, 2006), uma vez que Brâncio et al. (2003) observaram em cultivares de Panicum maximum maior porcentagem de lâminas foliares nos estratos mais baixos do cultivar de menor porte.

Sabe-se que a massa de forragem pode limitar o consumo dos animais em pastejo, no entanto, independentemente do cultivar e da altura do dossel, a quantidade de MST foi sempre superior a $2.000 \mathrm{~kg} /$ ha de MST (Tabela 3), o que, segundo Minson (1990), é considerado limite mínimo de forragem disponível em pasto de gramíneas tropicais para não restringir o consumo de forragem pelos animais. Entretanto, segundo Euclides (2000), quando há grande acúmulo sazonal de material morto, o consumo de forragem pelo animal não está correlacionado ao total de forragem disponível, mas, sim, às massas de MSV e de MSLF. Esse autor observou relação assintótica entre o ganho de peso dos animais e a massa de MSV em pastos de B. decumbens e B. brizantha cv. Marandu manejados sob lotação contínua. O ponto de máximo foi atingido quando a massa MSV foi de $1.100 \mathrm{~kg} / \mathrm{ha}$. A massa de MSV esteve sempre acima deste valor (Tabela 3), independentemente do cultivar e da altura do dossel, portanto, é possível que a disponibi- 
lidade de MSV também não tenha sido limitante ao consumo de forragem e ao ganho de peso dos animais.

Os pastos de capim-marandu e capim-xaraés apresentaram composição morfológica semelhante ( $\mathrm{P}>0,05)$, com médias e erros-padrão, respectivamente, de 27,7 (0,53); 29,6 $(0,33)$; e 43,2 $(0,69)$ para as porcentagens de lâmina foliar (PLF), de colmo (PCo) e de material morto (PMM). Para essas variáveis, não foram observadas interações $(\mathrm{P}>0,05)$ entre os efeitos de cultivar e de estação do ano; de cultivar, altura do dossel e estação do ano; e de cultivar e altura do dossel, exceto para PMM $(\mathrm{P}<0,01)$.

Nos pastos de capim-marandu manejados em diversas alturas, não houve diferença na PMM, no entanto, nos pastos de capim-xaraés, a PMM diminuiu de acordo com a intensidade de pastejo (Tabela 4). Além disso, ambos os cultivares apresentaram PMM semelhantes quando manejados a $25 \mathrm{~cm}$. O capim-xaraés apresentou a maior PMM quando manejado a $15 \mathrm{~cm}$ e a menor quando manejado a $40 \mathrm{~cm}$.

Verificou-se diferença $(\mathrm{P}<0,05)$ entre as alturas do dossel e influência da interação $(\mathrm{P}<0,01)$ altura do dossel × estação do ano sobre a composição morfológica dos pastos (Tabela 5). As maiores variações na composição morfológica dos pastos ocorreram durante o verão, quando houve decréscimos nas PLF e PCo e acréscimos na PMM à medida que aumentou a altura do dossel (Tabela 5). Essas alterações na estrutura durante o verão podem ser explicadas pela maior remoção de lâminas foliares e pelo maior controle do alongamento de colmo com o aumento da intensidade de pastejo, uma vez que, durante esse período, utilizou-se maior taxa de lotação (Tabela 2) na tentativa de se manterem as alturas pretendidas para o dossel.

No outono, as PLF e PMM foram semelhantes entre as alturas dos pastos. A PCo foi maior nos pastos manejados a $15 \mathrm{~cm}$, menor a $40 \mathrm{~cm}$ e semelhante nos pastos manejados a $25 \mathrm{~cm}$ (Tabela 5). As PLF nos pastos manejados a $40 \mathrm{~cm}$ de altura foram maiores durante o verão em comparação ao outono (Tabela 5). Molan (2004), apesar de não ter encontrado diferenças nas PLF em pastos de capim-marandu manejados a 10, 20, 30 e $40 \mathrm{~cm}$ de altura, observou que a PFL

Tabela 4 - Porcentagens de material morto (PMM) dos pastos de capins marandu e xaraés manejados em diversas alturas de dossel

\begin{tabular}{lcccc}
\hline & \multicolumn{3}{c}{ Altura $(\mathrm{cm})$} & \\
\cline { 2 - 4 } & 15 & 25 & 40 & Erro-padrão \\
\hline Marandu & $44,1 \mathrm{Ba}$ & $43,0 \mathrm{Aa}$ & $41,6 \mathrm{Aa}$ & 2,07 \\
Xaraés & $51,4 \mathrm{Aa}$ & $43,2 \mathrm{Ab}$ & $36,0 \mathrm{Bc}$ & 2,07 \\
Média & 47,8 & 43,1 & 38,8 & 1,47 \\
\hline
\end{tabular}

Médias seguidas de mesma letra minúscula, na linha, e de letra maiúscula, na coluna, não diferem $(P<0,05)$ pelo teste Tukey. durante o verão foi maior que no outono (em média, 28,4 e $19,7 \%$, respectivamente).

Os pastos manejados a $25 \mathrm{~cm}$ e $40 \mathrm{~cm}$ apresentaram maiores PCo e menores PMM durante o verão em comparação ao outono (Tabela 5). Nos pastos manejados a $15 \mathrm{~cm}$, no entanto, a PCo foi maior no outono que no verão e as PMM foram semelhantes entre as estações do ano (Tabela 5).

Outro fator que influencia o consumo é a facilidade de seleção e preensão da forrageira. Assim, as relações lâmina foliar:colmo (RFC) e material verde:material morto (RVM) são indicativos da facilidade com que a forragem é selecionada e apreendida pelo animal. As RFC e RVM foram semelhantes $(\mathrm{P}>0,05)$ entre os cultivares e apresentaram médias de $1,0(0,08)$ e 1,5 $(0,11)$, respectivamente. Também não houve efeitos da altura do dossel $(\mathrm{P}>0,73)$ e da estação do ano ( $\mathrm{P}>0,39)$ sobre a RFC. Molan (2004) também não encontrou variações nas RFC quando as alturas dos pastos de capim-marandu variaram de 10 a 40 cm e também observou RFC semelhantes entre as estações do ano. As RFC médias encontradas por este autor foram de 0,76 e 0,71 para o verão e outono, respectivamente. Não houve interações $(\mathrm{P}>0,05)$ entre os efeitos de cultivar e de altura; de cultivar e estação do ano; e de cultivar, altura de dossel e estação do ano sobre a RFC. No entanto, para a RVM, foram observados efeitos de altura do dossel $(\mathrm{P}<0,01)$, de estação do ano $(\mathrm{P}<0,01)$ e das interações cultivar $\times$ altura $(\mathrm{P}<0,04)$ e estação do ano $\times$ altura $(P<0,01)$. Entretanto, não foi observada interação $(\mathrm{P}>0,26)$ cultivar $\times$ estação do ano $\times$

Tabela 5 - Porcentagens de lâminas foliares, colmo e material morto de pastos de capins marandu e xaraés manejados em diversas alturas de dossel durante o verão e o outono

\begin{tabular}{lcccc}
\hline \multicolumn{4}{c}{ Altura (cm) } \\
\cline { 2 - 3 } & 15 & 25 & 40 & Erro-padrão \\
\cline { 2 - 3 } Verão & $26,4 \mathrm{Ab}$ & $28,6 \mathrm{Ab}$ & $34,1 \mathrm{Aa}$ & 1,85 \\
Outono & $24,6 \mathrm{Aa}$ & $27,8 \mathrm{Aa}$ & $24,5 \mathrm{Ba}$ & 1,85 \\
Média & 25,5 & 28,2 & 29,3 & 1,31 \\
\hline \multicolumn{5}{c}{ Colmo (\%) } \\
Verão & $24,1 \mathrm{Bb}$ & $32,1 \mathrm{Aab}$ & $35,8 \mathrm{Aa}$ & 1,69 \\
Outono & $29,4 \mathrm{Aa}$ & $25,2 \mathrm{Bb}$ & $28,0 \mathrm{Bab}$ & 1,69 \\
Média & 26,8 & 28,7 & 31,9 & 1,19 \\
\hline \multirow{4}{c}{ Material morto $(\%)$} \\
Verão & $49,5 \mathrm{Aa}$ & $39,3 \mathrm{Bb}$ & $30,1 \mathrm{Bc}$ & 2,07 \\
Outono & $46,0 \mathrm{Aa}$ & $46,9 \mathrm{Aa}$ & $47,4 \mathrm{Aa}$ & 2,07 \\
Média & 47,7 & 43,1 & 38,8 & 1,47 \\
\hline
\end{tabular}

Médias seguidas de mesma letra minúscula, na linha, e de letra maiúscula na coluna, não diferem $(P<0,05)$ pelo teste Tukey. 
altura. As RVM foram semelhantes entre as alturas de dossel no capim-marandu. No capim-xaraés, no entanto, o manejo a $40 \mathrm{~cm}$ resultou em RVM superior às obtidas com manejo a $25 \mathrm{~cm}$ e a $15 \mathrm{~cm}$ (Tabela 6) e à observada no pasto de capim-marandu manejado à mesma altura (Tabela 6).

Durante o verão, o pasto manejado com menor intensidade de pastejo ( $40 \mathrm{~cm}$ ) apresentou maior RVM em comparação àqueles manejados a 25 cm e a 15 cm de altura (Tabela 7), principalmente em virtude da maior PLF nestes pastos (Tabela 5). Durante o outono, no entanto, as RVM foram semelhantes entre os pastos manejados com diferentes intensidades de pastejo (Tabela 7).

A RVM registrada nos pastos manejados a $40 \mathrm{~cm}$ no verão foi maior que no outono. Nas outras intensidades de pastejo, as RVM foram semelhantes entre as estações do ano (Tabela 7), o que pode ser atribuído ao fato de que, no pasto submetido à menor intensidade de pastejo $(40 \mathrm{~cm})$, o animal remove menos lâmina foliar e a forragem recusada senesce e se transforma em material morto, aumentando gradativamente a PMM, efeito acumulativo que refletiu no outono (Tabela 5).

As ofertas de matéria seca total (MST) e matéria seca de lâminas foliares (MSLF) foram semelhantes $(\mathrm{P}>0,18)$ nos pastos de capim-marandu e capim-xaraés. Também não houve interações entre cultivar e altura do dossel $(\mathrm{P}>0,34)$; cultivar e estação do ano $(\mathrm{P}>0,40)$; e entre cultivar, altura do dossel e estação do ano $(\mathrm{P}>0,85)$ para estas variáveis. No entanto, houve diferenças $(\mathrm{P}<0,01)$ entre as alturas do

Tabela 6 - Relação material verde:material morto de pastos de capins marandu e xaraés manejados em diversas alturas de dossel

\begin{tabular}{lcccc}
\hline & \multicolumn{3}{c}{ Altura $(\mathrm{cm})$} & \\
\cline { 2 - 4 } & 15 & 25 & 40 & Erro-padrão \\
\hline Marandu & $1,30 \mathrm{Aa}$ & $1,41 \mathrm{Aa}$ & $1,53 \mathrm{Ba}$ & 0,27 \\
Xaraés & $0,98 \mathrm{Ab}$ & $1,42 \mathrm{Ab}$ & $2,47 \mathrm{Aa}$ & 0,27 \\
Média & 1,14 & 1,42 & 1,99 & 0,19 \\
\hline
\end{tabular}

Médias seguidas de mesma letra minúscula, na linha, e de letra maiúscula, na coluna, não diferem $(P<0,05)$ pelo teste Tukey.

Tabela 7 - Relação material verde:material morto de pastos de capins marandu e xaraés manejados em diversas alturas durante o verão e o outono

\begin{tabular}{lcccc}
\hline & \multicolumn{3}{c}{ Altura $(\mathrm{cm})$} & \\
\cline { 2 - 4 } & 15 & 25 & 40 & Erro-padrão \\
\hline Verão & $1,04 \mathrm{Ab}$ & $1,64 \mathrm{Ab}$ & $2,84 \mathrm{Aa}$ & 0,27 \\
Outono & $1,24 \mathrm{Aa}$ & $1,19 \mathrm{Aa}$ & $1,14 \mathrm{Ba}$ & 0,27 \\
Média & 1,14 & 1,42 & 1,99 & 0,19 \\
\hline
\end{tabular}

Médias seguidas de mesma letra minúscula, na linha, e de letra maiúscula, na coluna, não diferem $(P<0,05)$ pelo teste Tukey. dossel (Tabela 8). A maior oferta de MST foi observada no pasto manejado a $40 \mathrm{~cm}$ e as menores naqueles manejados a 15 e $25 \mathrm{~cm}$. A oferta de MSLF, no entanto, aumentou à medida que diminuiu a intensidade de pastejo.

Não foram observadas diferenças $(\mathrm{P}>0,15)$ para as variáveis associadas aos valores nutritivos dos pastos de capimmarandu e capim-xaraés. As médias e os erros-padrão da média foram: 10,4 (0,14); 59,0 (0,33); 74,1 (0,51); e 3,1 (0,05) para os teores de proteína bruta (PB) e para a digestibilidade in vitro de matéria orgânica (DIVMO), fibra detergente neutro (FDN) e lignina em detergente ácido (LDA), respectivamente. Também não houve interações entre cultivar e altura do dossel $(\mathrm{P}>0,63)$; cultivar e estação do ano $(\mathrm{P}>0,07)$; e entre cultivar, altura do dossel e estação do ano $(\mathrm{P}>0,10)$ para essas variáveis. Entretanto, houve diferenças $(\mathrm{P}<0,05)$ entre as alturas do dossel para os teores de PB e de FDN e interação $(\mathrm{P}<0,05)$ cultivar $\times$ altura para a DIVMO (Tabela 8$)$.

O menor conteúdo de PB foi observado no pasto manejado a $15 \mathrm{~cm}$ e os maiores naqueles manejados a $25 \mathrm{~cm}$ e a $40 \mathrm{~cm}$ (Tabela 8). Comportamento inverso foi encontrado por Andrade (2003), ou seja, maior conteúdo de PB para o capim-marandu manejado com maior intensidade de pastejo. O menor conteúdo de FDN foi observado no pasto manejado a $25 \mathrm{~cm}$ e os maiores naqueles manejados a $15 \mathrm{~cm}$ e a $40 \mathrm{~cm}$. Provavelmente, os pastos manejado a 15 $\mathrm{cm}$ e a $40 \mathrm{~cm}$ apresentavam maior quantidades de folhas velhas; no primeiro caso, as folhas novas foram consumidas pelos animais e, no segundo, a oferta de MSLF (Tabela 8) foi superior à capacidade de ingestão dos animais. Portanto, as folhas refugadas continuaram em processo de envelhecimento, o que ocasiona redução de seu conteúdo celular e acréscimo na parede celular (Euclides, 2000).

Os pastos de capim-marandu manejados a $15 \mathrm{~cm}$ e a $25 \mathrm{~cm}$ apresentaram maiores DIVMO em comparação àquele manejado a $40 \mathrm{~cm}$ (Tabela 9). Resultados seme-

Tabela 8 - Ofertas de matéria seca total (MST) e de matéria seca de lâminas foliares (MSLF) e teores de proteína bruta (PB) e fibra detergente neutro (FDN) das lâminas foliares de pastos de capins marandu e xaraés manejados em diversas alturas de dossel

\begin{tabular}{lcccc}
\hline & \multicolumn{3}{c}{ Altura $(\mathrm{cm})$} & \\
\cline { 2 - 4 } & 15 & 25 & 40 & Erro-padrão \\
\hline $\begin{array}{l}\text { MST } \\
\text { (kg MS/100 kg de PC·dia) }\end{array}$ & $15,0 \mathrm{~b}$ & $22,2 \mathrm{a}$ & 1,41 \\
$\begin{array}{l}\text { MSLF } \\
\text { (kg MS/100 kg de PC.dia) }\end{array}$ & & & \\
PB (\%) & $9,6 \mathrm{~b}$ & 11,1a & 10,4a & 0,43 \\
FDN (\%) & 75,0b & 73,1a & 74,5b & 0,28 \\
\hline
\end{tabular}

Médias seguidas de mesma letra na linha não diferem $(P<0,05)$ pelo teste Tukey. 
lhantes foram encontrados por Andrade (2003) em pastos de capim-marandu manejados de 10 a $40 \mathrm{~cm}$ de altura. $\mathrm{O}$ pasto de capim-xaraés apresentou maior DIVMO quando manejado a $25 \mathrm{~cm}$ (Tabela 9), o que está relacionado aos mesmos fatores que afetaram o conteúdo de FDN, uma vez que variações no conteúdo de parede celular resultam em variações semelhantes em DIVMO (Euclides, 2000). Ressalta-se que a DIVMO do capim-marandu manejado a $15 \mathrm{~cm}$ foi maior que o do capim-xaraés manejado na mesma altura, provavelmente em virtude da maior massa de lâminas foliares presente no pasto de capim-marandu (Tabela 3). Nas outras alturas de manejo, a DIVMO foi semelhante entre os pastos de capim-marandu e capim-xaraés (Tabela 9). Independentemente das alturas dos pastos, os teores de DIVMO foram semelhantes aos encontrados por Euclides et al. (2005), de 59,3 e 61,0\% para os capins xaraés e marandu, respectivamente, durante o período das águas.

O consumo de matéria seca (CMS) pelos animais foi semelhante entre os cultivares $(\mathrm{P}>0,17)$. Não foi observado efeito de altura do dossel $(\mathrm{P}>0,13)$, entretanto, houve interação $(\mathrm{P}>0,04)$ cultivares $\times$ altura do dossel. A ingestão de forragem pelos animais foi semelhante nos pastos de capim-marandu submetidos a diferentes intensidades de pastejo (Tabela 9). Os níveis de CMS estimados para os pastos de capim-marandu foram superiores aos encontrados por Sarmento (2003) e variaram entre 1,3 e 2,0\% do PV em pastos do mesmo capim manejados com alturas de $10 \mathrm{~cm}$ a $40 \mathrm{~cm}$.

No entanto, os animais no pasto de capim-xaraés manejado com $15 \mathrm{~cm}$ ingeriram menor quantidade de forragem (Tabela 9). A ingestão de MS pelos animais foi semelhante entre os pastos de capins marandu e xaraés, exceto quando manejados a $15 \mathrm{~cm}$. Além disso, os animais no pasto de capim-marandu ingeriram mais forragem em comparação aos mantidos no pasto de capim-xaraés (Tabela 9). Este baixo consumo de MS pode ser explicado pela menor quantidade de lâminas foliares (Tabela 3), maior PMM (Tabela 4) e pelo menor RFC (Tabela 6) observado no capimxaraés manejado a $15 \mathrm{~cm}$ de altura; uma vez que, segundo Euclides (2000), mesmo quando a OFMS é alta (Tabela 8), o material morto e/ou colmo podem limitar a facilidade de seleção e de preensão e o consumo de forragem pelos animais.

A taxa de bocado (TB) foi semelhante $(\mathrm{P}>0,87)$ entre os cultivares (em média, 47 bocados/minuto). Não houve interação $(\mathrm{P}>0,38)$ efeitos de cultivar $\times$ altura de pastejo, no entanto, a taxa de bocado foi menor $(\mathrm{P}<0,01)$ para os pastos manejados a $25 \mathrm{~cm}$ de altura (Tabela 10). Essa variação na TB foi menor que a encontrada por Sarmento (2003), de 46,3 a 17,5 bocados/minutos, para pastos de capim-marandu manejados entre 10 e $40 \mathrm{~cm}$ de altura. Uma vez que a taxa de bocado permite estimar a facilidade com que o animal seleciona e apreende a forrageira, provavelmente os animais nos pastos manejados a $15 \mathrm{~cm}$ tiveram maior dificuldade de seleção e de preensão da forragem, em razão da menor oferta de lâminas foliares (Tabela 8) e do maior PMM (Tabela 5). A maior dificuldade de pastejo encontrada pelos animais nos pastos manejados a $40 \mathrm{~cm}$ de altura provavelmente foi conseqüência da maior presença de colmos (Tabela 5).

Não houve diferenças nos tempos de pastejo (TP) dos animais nos pastos de capins marandu e xaraés ( $\mathrm{P}>0,79)$, que foram em média 570 minutos por dia. Tempos de pastejo superiores foram encontrados por Sarmento (2003), que observou variação de 610 a 750 minutos por dia quando a altura do dossel de capim-marandu decresceu de 40 para $10 \mathrm{~cm}$. Também não houve efeitos de interação cultivar $\times$ altura do dossel $(\mathrm{P}>0,83)$ nem diferenças nos tempos de pastejo dos animais em pastos manejados com diferentes alturas do dossel $(\mathrm{P}>0,23)$, apesar de ter havido decréscimo de 50 minutos/dia nos pastos manejados a $25 \mathrm{~cm}$ (Tabela 10).

Tabela 9 - Digestibilidade in vitro da matéria orgânica (DIVMO) de lâminas foliares e consumo de matéria seca (CMS) em pastos de capins marandu e xaraés manejados em diversas alturas de dossel

\begin{tabular}{|c|c|c|c|c|}
\hline & \multicolumn{3}{|c|}{ Altura $(\mathrm{cm})$} & Erro-padrão \\
\hline \multicolumn{5}{|c|}{ DIVMO (\%) } \\
\hline Marandu & $60,0 \mathrm{aA}$ & $60,7 \mathrm{aA}$ & $56,6 \mathrm{bA}$ & 0,56 \\
\hline Xaraés & $57,6 \mathrm{bB}$ & $61,3 \mathrm{aA}$ & $57,4 \mathrm{bA}$ & 0,56 \\
\hline \multicolumn{5}{|c|}{ CMS (kg de matéria seca por 100 kg PC) } \\
\hline Xaraés & $1,80 \mathrm{Bb} \pm 0,13$ & $2,32 \mathrm{Aa} \pm 0,17$ & $2,20 \mathrm{Aa} \pm 0,13$ & $2,11 \pm 0,06$ \\
\hline
\end{tabular}

Médias seguidas de mesma letra minúscula na linha, e de letra maiúscula na coluna, não diferem $(P<0,05)$ pelo teste Tukey. 
Tabela 10 - Tempo de pastejo (TP) e taxa de bocado (TB) em pastos de capins marandu e xaraés manejados em diferentes alturas durante o verão

\begin{tabular}{lccc}
\hline & \multicolumn{3}{c}{ Altura do dossel (cm) } \\
\cline { 2 - 4 } & \multicolumn{1}{c}{15} & 25 & 40 \\
\hline TB & $48,3 a(0,85)$ & $44,0 b(1,03)$ & $47,9 a(0,91)$ \\
(bocados/minuto) & & & \\
TP (minuto/dia) & 585a (25) & 535a (25) & 590a (24) \\
\hline
\end{tabular}

Médias seguidas de mesma letra minúscula, na linha, e de letra maiúscula, na coluna, não diferem $(P<0,05)$ pelo teste Tukey.

Valores entre parênteses se referem ao erro-padrão da média.

O aumento na taxa de bocado e/ou no tempo de pastejo com o objetivo de compensar a redução na massa da bocado em condições de pastejo com oferta restrita de forragem ou de estrutura do dossel desfavorável ao pastejo pelo animal é amplamente descrito na literatura (Arnold, 1987; Hodgson, 1990; Brâncio et al., 2003; Palhano et al., 2006), no entanto, os aumentos no tempo de pastejo e na taxa de bocado não foram suficientes para impedir a redução no consumo de forragem pelos animais em pastos capim-xaraés manejado a $15 \mathrm{~cm}$ (Tabela 9). Como não houve diferenças nos teores de FDN (Tabela 8) e DIVMO (Tabela 9) para os pastos de capim-xaraés manejados a $15 \mathrm{~cm}$ e a $40 \mathrm{~cm}$, provavelmente o consumo de matéria seca pelos animais no pasto de capimxaraés manejado a $15 \mathrm{~cm}$ foi limitado pelas características estruturais do pasto (Tabelas 3, 4 e 6).

Independentemente das alturas, os animais no pasto de capim-marandu ganharam mais peso $(\mathrm{P}<0,03)$ que aqueles em pasto de capim-xaraés - médias e erros-padrão de 570 (24) e 490 (24) g/animal/dia, respectivamente. Euclides et al. (2005) também observaram maior ganho de peso em animais em pastos de capim-marandu em comparação a animais em pastos de capim-xaráes durante o período das águas.

Não foi observada interação $(\mathrm{P}>0,90)$ cultivar $\times$ altura, no entanto, no verão, o ganho diário médio (GMD) diminuiu $(\mathrm{P}<0,01)$ à medida que se aumentou a intensidade de pastejo (Tabela 11). Ressalta-se que os GMD registrados nos pastos de capim-marandu durante o verão foram de 390, 580 e $850 \mathrm{~g} /$ animal/dia para os pastos manejados a 15, 25 e $40 \mathrm{~cm}$ de altura do dossel e estão dentro da amplitude de variação encontrada por Andrade (2003), de 190, 510, 750 e 930 g/ animal/dia, respectivamente, em pastos de capim-marandu manejados a 10, 20, 30 e $40 \mathrm{~cm}$ de altura do dossel na mesma época do ano.

Não foi observado efeito da estação do ano $(\mathrm{P}>0,68)$ e da interação $(P>0,15)$ cultivar $\times$ estação do ano, entretanto, houve efeito $(\mathrm{P}<0,01)$ da interação altura do dossel $\times$ estação do ano sobre o ganho médio diário. Durante o verão, o GMD aumentou à medida que a intensidade de pastejo
Tabela 11 - Ganho médio diário (g/animal/dia) dos animais e taxas de lotação (UA/ha) nos pastos de capins marandu e xaraés manejados em diversas alturas durante o verão e o outono

\begin{tabular}{|c|c|c|c|c|}
\hline & \multicolumn{3}{|c|}{ Altura (cm) } & \multirow[b]{2}{*}{ Erro-padrão } \\
\hline & 15 & 25 & 40 & \\
\hline \multicolumn{5}{|c|}{ Ganho médio diário (g/animal/dia) } \\
\hline Verão & $300 \mathrm{Ac}$ & $510 \mathrm{Ab}$ & $800 \mathrm{Aa}$ & 24 \\
\hline Outono & $475 \mathrm{Aa}$ & $560 \mathrm{Aa}$ & $535 \mathrm{Ba}$ & 24 \\
\hline Média & 388 & 354 & 671 & 24 \\
\hline \multicolumn{5}{|c|}{ Taxa de lotação (UA/ha) } \\
\hline Verão & $5,9 \mathrm{Aa}$ & $4,3 \mathrm{Ab}$ & $3,4 \mathrm{Ac}$ & 0,12 \\
\hline Outono & $2,4 \mathrm{Ba}$ & $2,4 \mathrm{Ba}$ & $2,6 \mathrm{Aa}$ & 0,12 \\
\hline Média & 4,2 & 3,4 & 3,0 & 0,09 \\
\hline
\end{tabular}

Médias seguidas de mesma letra minúscula, na linha, e de letra maiúscula, na coluna, não diferem $(P<0,05)$ pelo teste Tukey.

diminuiu, no entanto, durante o outono, não foram observadas diferenças no GMD entre os pastos manejados em diversas alturas (Tabela 11), o que pode está relacionado às maiores variações na estrutura do dossel forrageiro durante o verão (Tabelas 5 e 7).

A taxa de lotação não foi influenciada pela interação cultivar $\times$ altura do dossel $(\mathrm{P}>0,27)$, no entanto, houve interação $(\mathrm{P}<0,01)$ altura do dossel $\times$ estação do ano (Tabela 11). Durante o verão, houve acréscimo na TL à medida que se aumentou a intensidade de pastejo, ou seja, quanto mais baixo o pasto, maior número de animais foi necessário para mantê-lo na altura pretendida; no entanto, durante o outono, as TL foram semelhantes para as diferentes alturas do dossel (Tabela 11). Provavelmente, isso tenha ocorrido como conseqüência da menor taxa de acúmulo de forragem aliada à falha em gerar condições contrastantes na estrutura do dossel, durante esta época do ano (Tabelas 5 e 7).

Independentemente da altura do dossel, os pastos de capim-xaraés suportaram maior $(\mathrm{P}<0,01)$ taxa de lotação (TL). Euclides et al. (2005) também observaram maior capacidade de suporte em pasto de capim-xaraés em comparação ao capim-marandu no período das águas. A taxa de lotação foi maior $(\mathrm{P}<0,01)$ durante o verão que no outono (Tabela 14), também foi observada interação $(P<0,01)$ cultivares $\times$ estação do ano; durante o verão a TL foi maior para o capim-xaráes. No outono, por outro lado, os dois cultivares suportaram o mesmo número de animais (Tabela 12). Este fato poderia ser explicado pela tendência $(\mathrm{P}<0.08)$ de maior taxa de acúmulo de forragem no pasto de capimxaraés durante o verão quando comparado ao capimmarandu no mesmo período. As médias e o desvio-padrão da média de 120,7 e 96,6 (9,5) kg/ha.dia de matéria seca, respectivamente. Ressalta-se, que durante o outono, as 
Tabela 12 - Taxas de lotação (UA/ha) de pastos de capins marandu e xaraés durante o verão e o outono

\begin{tabular}{lccc}
\hline & Capim-marandu & Capim-xaraés & Média \\
\hline Verão & 4,0Ab $(0,1)$ & 5,1Aa $(0,1)$ & $4,5(0,08)$ \\
Outono & 2,4Ba $(0,1)$ & 2,5Ba $(0,1)$ & $2,5(0,08)$ \\
Média & $3,2(0,07)$ & $3,8(0,07)$ & \\
\hline
\end{tabular}

Médias seguidas de mesma letra minúscula, na linha, e de letra maiúscula, na coluna, não diferem $(P<0,05)$ pelo teste Tukey.

Tabela 13 - Produtividades ( $\mathrm{kg} / \mathrm{ha}$ ) de pastos de capins marandu e xaraés manejados em diferentes alturas durante 0 verão e o outono

\begin{tabular}{lcccc}
\hline & \multicolumn{3}{c}{ Altura $(\mathrm{cm})$} & \\
\cline { 2 - 4 } & 15 & 25 & 40 & Erro-padrão \\
\hline Capim-marandu & $360 \mathrm{Ab}$ & $419 \mathrm{Aa}$ & $421 \mathrm{Aa}$ & 11,2 \\
Capim-xaraés & $330 \mathrm{Ab}$ & $390 \mathrm{Ab}$ & $479 \mathrm{Aa}$ & 11,2 \\
Média & 345 & 404 & 450 & 8,0 \\
\hline
\end{tabular}

Médias seguidas de mesma letra minúscula, na linha, e de letra maiúscula, na coluna, não diferem $(P<0,05)$ pelo teste Tukey.

taxas de acúmulo de forragem semelhantes $(\mathrm{P}>0,89)$ entre ambos os cultivares.

A produtividade dos pastos foi semelhante $(\mathrm{P}>0,66)$ entre os cultivares, no entanto, houve efeito $(\mathrm{P}<0,03) \mathrm{da}$ interação cultivar $\times$ altura do dossel. Os pastos de capimmarandu manejados a 25 e $40 \mathrm{~cm}$ apresentaram produtividades semelhantes, superiores às obtidas no pasto manejado a $15 \mathrm{~cm}$. No capim-xaraés, no entanto, as produtividades obtidas com os manejos a $15 \mathrm{~cm}$ e $25 \mathrm{~cm}$ de altura foram semelhantes, porém inferiores à observada no pasto manejado a $40 \mathrm{~cm}$ (Tabela 13). De modo geral, nota-se equilíbrio na produtividade do capim-marandu entre 25 e $40 \mathrm{~cm}$. Este resultado confirma o encontrado por Andrade (2003) de que o ponto de equilíbrio entre os ganhos de peso por animal e por área ocorreram entre 30 e $40 \mathrm{~cm}$ de altura para pasto desta gramínea.

O ponto de equilíbrio no pasto de capim-xaraés, no entanto, não foi alcançado na faixa de altura do dossel estudada (Tabela 14). Assim, considerando a massa de lâminas foliares (Tabela 3), a estrutura do dossel (Tabelas 4 e 6) e a ingestão de forragem (Tabela 11), conclui-se que esse cultivar deveria ser manejado com altura do dossel superior à do capim-marandu, em virtude do maior porte do capim-xaraés em relação ao capim-marandu (Silveira, 2006). Padrão análogo de respostas foi descrito para esses cultivares sob pastejo intermitente (Pedreira et al., 2006; Sarmento, 2007). Maiores taxas de acúmulo de forragem e estrutura de dossel mais favorável ao pastejo foram obtidas no capim-xaraés a 30 cm (Pedreira et al., 2006) e no capimmarandu a 25 cm (Sarmento, 2007).

\section{Conclusões}

A altura do pasto, para os capins marandu e xaraés, pode ser usada no manejo voltado para produção eficiente e sustentável de carne em sistemas de pastejo. Com base nas características estruturais do dossel, no consumo de forragem e na produtividade, estes capins requerem práticas de manejo diferenciadas. O capim-marandu deve ser manejado entre $25 \mathrm{~cm}$ e $40 \mathrm{~cm}$ de altura e o capim-xaraés a $40 \mathrm{~cm}$ de altura.

\section{Agradecimento}

À Fundect, pela bolsa de estudos e pelo apoio financeiro. À Embrapa Gado de Corte, pela infra-estrutura e mão-deobra. Ao Conselho Nacional de Desenvolvimento Científico e Tecnológico, pelas bolsas de pesquisa.

\section{Literatura Citada}

ANDRADE, F.M.E. Produção de forragem e valor alimentício do capim-Marandu submetido a regimes de lotação contínua por bovinos de corte. Piracicaba: Escola Superior de Agricultura “Luiz de Queiroz”, 2003. 125p. Dissertação (Mestrado em Agronomia) - Escola Superior de Agricultura "Luiz de Queiroz”, 2003.

ARNOLD, G.W. Influence of the biomass, botanical composition and sward height of annual pastures on foraging behaviour of sheep. Journal of Applied Ecology, v.24, p. 759-772, 1987.

BARBOSA, R.A.; NASCIMENTO JR., D.; EUCLIDES, V.P.B. et al. Capim-tanzânia submetido a combinações entre intensidade e freqüência de pastejo. Pesquisa Agropecuária Brasileira, v.42, p.329-340, 2007.

BRÂNCIO, P.A.; EUCLIDES, V.P.B.; NASCIMENTO JR., D. et al. Avaliação de três cultivares de Panicum maximum Jacq. sob pastejo: disponibilidade de forragem, altura do resíduo pós-pastejo e participação de folhas, colmos e material morto. Revista Brasileira de Zootecnia, v.32, n.1, p.55-63, 2003.

CARNEVALLI, R.A.F.; DA SILVA, S.C.; CARVALHO, C.A.B. et al. Desempenho de ovinos e respostas de pastagens de Florakirk (Cynodon spp.) submetidas a regimes de desfolha sob lotação contínua. Boletim da Indústria Animal, v.57, p.53-63, 2000.

CARNEVALLI, R.A.F.; DA SILVA, S.C.; CARVALHO, C.A.B. et al. Desempenho de ovinos e respostas de pastagens de coastcross (Cynodon spp.) submetidas a regimes de desfolha sob lotação contínua. Pesquisa Agropecuária Brasileira, v.36, p.919927, 2001a.

CARNEVALLI, R.A.F.; DA SILVA, S.C.; FAGUNDES, J.L. et al. Desempenho de ovinos e respostas de pastagens de Tifton-85 (Cynodon spp.) submetidas a regimes de desfolha sob lotação contínua. Scientia Agrícola, v.58, p.7-15, 2001 b.

CARNEVALLI, R.A.; DA SILVA, S.C.; BUENO, A.A.O. et al. Herbage production and grazing losses in Panicum maximum cV. Mombaça under four grazing managements. Tropical Grasslands, v.40, p.165-176, 2006.

DIFANTE, G.S. Desempenho de novilhos, comportamento ingestivo e consumo voluntário de “Panicum maximum cv. Tanzânia” sob regime de desfolhação intermitente. Viçosa, MG: Universidade Federal de Viçosa, 2005. 100p. Tese (Doutorado em Zootecnia) - Universidade Federal de Viçosa, 2005. 
EUCLIDES, V.P.B. Alternativas para intensificação da produção de carne bovina em pastagem. Campo Grande: Embrapa Gado de Corte, 2000. 65p.

EUCLIDES, V.P.B.; MACEDO, M.C.M.; VALLE, C.B. et al. Animal performance and productivity of new ecotypes of Brachiaria brizantha in Brazil. In: INTERNATIONAL GRASSLAND CONGRESS, 20., 2005, Dublin. Proceedings... Wageningen: Wageningen Academic Publishers, 2005. p.106.

EMPRESA BRASILEIRA DE PESQUISA E AGROPECUÁRIA EMBRAPA. Centro Nacional de Pesquisa de Solos (Rio de Janeiro, RJ). Sistema brasileiro de classificação de solos. Brasília: Embrapa-SPI; Rio de Janeiro: Embrapa-CNPS, 1999. 412p.

FAGUNDES, J.L.; SILVA, S.C.; PEDREIRA, C.G.S. et al. Intensidades de pastejo e a composição morfológica de pastos de Cynodon spp. Scientia Agricola, v.56, n.4, 1999.

GOMIDE, J.A.; GOMIDE, C.A.M. Utilização e manejo de pastagens. In: REUNIÃO ANUAL DA SOCIEDADE BRASILEIRA DE ZOOTECNIA, 38., 2001, Piracicaba. Anais... Piracicaba: Sociedade Brasileira de Zootecnia, 2001. (CD-ROM).

HODGSON, J. Ingestive behavior. In: LEAVER, J.D. (Ed.) Herbage intake handbook. Hurley: British Grassland Society, 1982, p.113-38.

HODGSON, J. Grazing management: science into practice. New York: John Wiley \& Sons, 1990. 203p.

LUPINACCI, A.V. Reservas orgânicas, índice de área foliar e produção de forragem em pastos de Brachiaria brizantha cv. Marandu, submetida a intensidades de pastejo por bovinos de corte. Piracicaba: Escola Superior de Agricultura "Luiz de Queiroz”, 2002. 160p. Dissertação (Mestrado em Agronomia) - Escola Superior de Agricultura "Luiz de Queiroz”, 2002.

MACEDO, M.C.M. Pastagens no ecossistema cerrados: evolução das pesquisas para o desenvolvimento sustentáveis. In: REUNIÃO ANUAL DA SOCIEDADE BRASILEIRA DE ZOOTECNIA, 42., 2005, Goiânia. Anais... Goiânia: Sociedade Brasileira de Zootecnia, 2005. p.56-84.

MARTEN, G.C.; SHENK, J.S.; BARTON II, F.E. Near infrared reflectance spectroscopy (NIRS), analysis quality. Washington: USDA, 1985. 110p. (Agriculture Handbook, 643).

MINSON, D.J. Forage in ruminant nutrition. San Diego: Academic Press, 1990. 483p.

MOLAN, L.K. Estrutura do dossel, interceptação luminosa e acúmulo de forragem em pastos de capim-Marandu submetidos a alturas de pastejo por meio de lotação contínua. Piracicaba: Escola Superior de Agricultura "Luiz de Queiroz", 2004. 180p. Dissertação (Mestrado em Agronomia) - Escola Superior de Agricultura "Luiz de Queiroz”, 2004.

PALHANO, A.L.; CARVALHO, P.C.F.; DITTRICH, J.R. et al. Padrões de deslocamento e procura por forragem de novilhas leiteiras em pastagem de capim-mombaça. Revista Brasileira de Zootecnia, v.35, n.6, p.2253-2259, 2006.
PEDREIRA, B.C.; PEDREIRA, C.G.S.; DA SILVA, S.C. Estrutura do dossel e acúmulo de forragem de Brachiaria brizantha cultivar Xaraés em resposta a estratégias de pastejo. Pesquisa Agropecuária Brasileira, v.42, p.281-287, 2006.

SARMENTO, D.O.L. Comportamento ingestivo de bovinos em pastos de capim marandu a regimes de lotação contínua. Piracicaba: Escola Superior de Agricultura "Luiz de Queiroz", 2003. 76p. Dissertação (Mestrado em Agronomia) - Escola Superior de Agricultura “Luiz de Queiroz”/Universidade de São Paulo, 2003.

SARMENTO, D.O.L. Produção, composição morfológica e valor nutritivo da forragem em pastos de Brachiaria brizantha (Hochst ex A. Rich) Stapf. cv Marandu submetidos a estratégias de pastejo rotativo por bovinos de corte. Piracicaba: Escola Superior de Agricultura "Luiz de Queiroz", 2007. 144p. Tese (Doutorado em Agronomia) - Escola Superior de Agricultura “Luiz de Queiroz", 2007.

SBRISSIA, A.F. Morfogênese, dinâmica do perfilhamento e do acúmulo de forragem em pastos de capim-marandu sob lotação contínua. Piracicaba: Escola Superior de Agricultura "Luiz de Queiroz", 2004. 171p. Tese (Doutorado em Agronomia) - Escola Superior de Agricultura "Luiz de Queiroz”, 2004.

SILVEIRA, M.C.T. Caracterização morfogênica de oito cultivares do gênero Brachiaria e dois do gênero Panicum. Viçosa, MG: Universidade Federal de Viçosa, 2006. 91p. Dissertação (Mestrado em Zootecnia) - Universidade Federal de Viçosa, 2006.

STATISTICAL ANALYSIS SYSTEM - SAS. SAS/STAT. User Software: changes and enhancements thorough release. Version 6.11. Cary: SAS Institute, 1996. (CD-ROM).

STOBBS, T.H. Automatic measurement of the grazing time by diary cows on tropical grass and legume pastures. Tropical Grassland, v.4, n.3, p237-244, 1970.

VALADARES FILHO, S.C.; PAULINO, P.V.R.; SAINZ, R.D. Desafios metodológicos para determinação das exigências nutricionais de bovinos de corte no Brasil. In: REUNIÃO ANUAL DA SOCIEDADE BRASILEIRA DE ZOOTECNIA, 42. 2005, Goiânia. Anais... Goiânia: Sociedade Brasileira de Zootecnia, 2005. p.261-287.

WILLIANS, C.H.; DAVID, D.J.; ISMAA, O. The determination of chromic oxide in feces samples by atomic absorption spectrophotometry. Journal of Agriculture Science, v.59, n.3, p.81-85, 1962.

ZEFERINO, C.V. Morfogênese e dinâmica do acúmulo de forragem em pastos de capim-marandu [Brachiaria brizantha (Hochst. ex A. Rich) cv. Marandu] submetidos a regimes de lotação intermitente por bovinos de corte. Piracicaba: Escola Superior de Agricultura "Luiz de Queiroz", 2006. Tese (Doutorado em Agronomia) - Escola Superior de Agricultura "Luiz de Queiroz”, 2006. 